\title{
Molecular electrostatic potential analysis of non-covalent complexes
}

\author{
PADINJARE VEETIL BIJINA and CHERUMUTTATHU H SURESH*(D) \\ Chemical Sciences and Technology Division and Academy of Scientific \& Innovative Research (AcSIR), \\ CSIR-National Institute for Interdisciplinary Science and Technology, Trivandrum, Kerala 695 019, India \\ e-mail: sureshch@niist.res.in
}

MS received 2 June 2016; revised 24 August 2016; accepted 24 August 2016

\begin{abstract}
Ab initio MP4/Aug-cc-pvDZ//MP2/6-311++g(d,p) level interaction energy ( $\left.\mathrm{E}_{\text {int }}\right)$ and molecular electrostatic potential analysis (MESP) of a large variety of non-covalent intermolecular complexes, viz. tetrel, chalcogen, pnicogen, halogen, hydrogen, dihydrogen and lithium bonded complexes have been reported. The electronic changes associated with the non-covalent complex formation is monitored in terms of MESP mini$\operatorname{mum}\left(V_{\min }\right)$ in the free and complexed states of the donor and acceptor molecules as well as in terms of MESP at the donor and acceptor atoms $\left(V_{n}\right)$ of the free monomers and complexes. The change in $V_{\min }$ or $V_{n}$ on the donor molecule $\left(\Delta V_{\min }(\mathrm{D})\right.$ or $\left.\Delta V_{\mathrm{n}}(\mathrm{D})\right)$ during complex formation is proportional to its electron donating ability while such a change on the acceptor molecule $\left(\Delta V_{\min }(\mathrm{A})\right.$ or $\left.\Delta V_{\mathrm{n}}(\mathrm{A})\right)$ is proportional to its electron accepting ability. Further, the quantities $\Delta \Delta V_{\min }=\Delta V_{\min }(\mathrm{D})-\Delta V_{\min }(\mathrm{A})$ and $\Delta \Delta V_{\mathrm{n}}=\Delta V_{\mathrm{n}}(\mathrm{D})-\Delta V_{\mathrm{n}}(\mathrm{A})$ have shown strong linear correlations with $E_{\text {int }}$ of the complex ( $E_{\text {int }}$ values fall in the range 0.7 to $46.2 \mathrm{kcal} / \mathrm{mol}$ for 54 complexes) and suggest that the intermolecular non-covalent interactions in a wide variety of systems can be monitored and assessed in terms of change in MESP due to complex formation in the gas phase. With the incorporation of solvent effect in the calculation, charged systems showed significant deviations from the linear correlation. The MESP based analysis proposes that the large variety of intermolecular non-covalent complexes considered in this study can be grouped under the general category of electron donor-acceptor (eDA) complexes.
\end{abstract}

Keywords. Non-covalent complex; hydrogen bond; halogen bond; dihydrogen bond; pnicogen bond; tetrel bond; lithium bond; chalcogen bond; molecular electrostatic potential.

\section{Introduction}

Non-covalent interactions between molecules, which span a wide range of strength from weak van der Waals interactions between non-polar entities to ionion interactions that can be very strong, play a key role in crystal engineering, molecular recognition and controls the structures adopted by molecules and their transition from one conformer to other. ${ }^{1-6}$ These interactions include hydrogen (HB), ${ }^{4,9}$ dihydrogen (DHB), ${ }^{10-12}$ halogen (XB), ${ }^{13-19}$ pnicogen (PB), ${ }^{20-22}$ chalcogen $(\mathrm{CB}),^{23-28}$ tetrel $(\mathrm{TB}),{ }^{29-33}$ and lithium $(\mathrm{LiB})^{34-36}$ bond. Among them, the most extensively studied one is hydrogen bonding interaction. The conventional $\mathrm{HBs}$, where the proton donor and acceptor atoms are electronegative atoms like $\mathrm{N}, \mathrm{O}$ and $\mathrm{F}$, have been generalized in recent researches in directions such as the $\mathrm{C}$, a less electronegative atom than the conventional proton donor, can act as proton donor

\footnotetext{
*For correspondence

Celebrating 100 years of Lewis Chemical Bond
}

and the hydrogen bond acceptors can donate electron density via $\pi$ bonds, $\sigma$ bonds, metal atoms and even another hydrogen atom rather than the conventional lone pairs. ${ }^{37,38}$

Many theoretical models have been developed to account the features of hydrogen bond. Gilli and coworkers proposed the electrostatic-covalent model of hydrogen bonding. According to them, weak hydrogen bonds are electrostatic in nature and become more covalent with increasing bond strength. ${ }^{39,40}$ Coulson divided the columbic attraction energy of hydrogen bond into four factors: electrostatic, covalent, and repulsive and dispersion contributions. ${ }^{41}$ Pimentel and McClellan introduced the MO model for hydrogen bonding. ${ }^{42}$ They suggested that hydrogen bonds can be considered as three-centre four- electron bonds. Crabtree and co-workers introduced the term dihydrogen bond which describes the interaction of the type $\mathrm{X}-\mathrm{H} \cdots \mathrm{H}-\mathrm{Y}$, where $\mathrm{X}$ is more electronegative than hydrogen and $\mathrm{Y}$, usually transition metals or boron atom, is less electronegative than hydrogen. ${ }^{43,44} \mathrm{LiB}$ interactions designated as $\mathrm{X}$....Li-Y, where $\mathrm{X}$ is a species with a region of high electron density, is a counter part to the $\mathrm{HB}$ 
and have properties somewhat similar to $\mathrm{HB} .{ }^{45} \mathrm{As} \mathrm{Li}$ is more electropositive than hydrogen, $\mathrm{Li}-\mathrm{Y}$ bond will be more ionic compared to $\mathrm{H}-\mathrm{Y}$ bond and therefore $\mathrm{LiB}$ bonds appear stronger than $\mathrm{HB}$.

The interactions $\mathrm{XB}, \mathrm{TB}, \mathrm{CB}$ and $\mathrm{PB}$ can be classified as " $\sigma$-hole bonds" proposed by Politzer and Murray. ${ }^{13,46,47}$ The term " $\sigma$-hole" usually refers to an empty outer lobe of a p orbital involved in forming a covalent bond, especially when one of the atoms is highly electronegative, that corresponds to a positive region of the molecular electrostatic potential (MESP) and can act as an electron-pair acceptor in non-covalent interactions. Tetrel, pnicogen, chalcogen and halogen bonds, where the elements respectively are from group 14 to 17 acting as electron acceptors, are in some way analogous to hydrogen bonding. The positive " $\sigma$ hole" on the outermost surface of these elements (which are $\sigma$-bonded to usually highly electronegative atoms) interacts with negative sites on the other molecules. These interactions are directional due to the localization of the electron acceptor site ( $\sigma$-hole) on the extension of the covalent bond. ${ }^{48}$

MESP which can be calculated from theoretically derived electron density or measured experimentally has been proven useful in understanding the interactive behaviour and properties of molecules. ${ }^{49-60}$ The most negative-valued points in the MESP topography, usually indicated with the notation $V_{\min }$ is widely used to gauge the electron donating properties of a molecule. ${ }^{61}$ Similarly, MESP at a nucleus, referred to as $V_{\mathrm{n}}$ is also used as a parameter to measure the interactive behaviour of a molecule with respect to a particular atom towards the electron rich/electron deficient site of another molecule. ${ }^{50,51}$ Since $V_{\mathrm{n}}$ measures MESP at the position of atom $\mathrm{A}$ due to the rest of the nuclei and all the electrons, its interactions with other chemical entities are accurately reflected on changes in $V_{\mathrm{n}}$ values. $^{54}$ In a recent study based on MESP analysis, Mohan and Suresh have suggested that the definition of electron donor-acceptor (eDA) interaction holds good for the hydrogen (HB), halogen (XB) and dihydrogen bonded (DHB) non-covalent dimers. ${ }^{61}$ They used MESP features to quantify the donating power of the electron donating atom as well as the accepting power of the electron accepting atom (usually the $\mathrm{H}$ atom). Further, they reported a strong linear correlation between a MESP based parameter $\Delta \Delta V_{\mathrm{n}}$ (difference of the change of MESP at nuclei of donor and acceptor atoms due to complex formation) and interaction energy, $E_{\text {int }}$ for a large variety of the noncovalent dimers in the categories HB, DHB, and XB. The MESP based eDA concept proposed by Mohan and Suresh has unified the HB, DHB, and XB non-covalent complexes in a single category, the eDA complex. ${ }^{61}$ In the present work, the $\Delta \Delta V_{\mathrm{n}}$ versus $\mathrm{E}_{\text {int }}$ correlation has been analysed for a large variety of non-covalent complexes including the hitherto unexplored $\mathrm{CB}, \mathrm{TB}$, $\mathrm{PB}$ and $\mathrm{LiB}$ complexes. This work will show that $\mathrm{eDA}$ concept is applicable for all these systems.

\section{Computational Methods}

The complexes selected for this study include hydrogen (HB), dihydrogen (DHB), halogen (XB), chalcogen $(\mathrm{CB})$, pnicogen $(\mathrm{PB})$, tetrel $(\mathrm{TB})$ and lithium $(\mathrm{LiB})$ bonded dimers. The optimization of the geometry of all these systems (six examples from each category) and their vibrational frequency analysis have been done at MP2/6-311++G(d,p) level of theory. All the structures correspond to minima on the potential energy surface. Single point energy calculation using MP4/ Aug-cc-pvDZ level of theory is performed on MP2/6$311++\mathrm{G}(\mathrm{d}, \mathrm{p})$ level optimized structures to obtain more accurate energy values. Moreover, the counterpoise procedure of Boys and Bernardi ${ }^{62}$ has been used at MP4/Aug-cc-pvDZ level to obtain the basis set superposition error (BSSE). The BSSE-corrected binding energy $\left(\mathrm{E}_{\mathrm{int}}\right)$ of the complexes is calculated as the difference between the energy of the complexes and their constituent monomers.

Molecular electrostatic potential (MESP) arise due to the static charge distribution of the molecule which at any point in the space with position vector $\mathbf{r}$ can be calculated using the equation,

$$
V(\mathbf{r})=\sum_{\mathrm{A}}^{\mathrm{N}} \frac{\mathrm{Z}_{\mathrm{A}}}{\left|\mathbf{r}-\mathbf{R}_{\mathrm{A}}\right|}-\int \frac{\rho\left(\mathbf{r}^{\prime}\right) \mathrm{d}^{3} \mathbf{r}^{\prime}}{\left|\mathbf{r}-\mathbf{r}^{\prime}\right|}
$$

where $\rho\left(\mathbf{r}^{\prime}\right)$ is a continuous electron density and $Z_{\mathrm{A}}$ is the charge on nucleus of atom A located at a distance $\mathbf{R}_{\mathrm{A}} \cdot{ }^{54,58}$ The MESP at the nucleus $\left(V_{n}\right)$ of a particular atom $\mathrm{A}$ in the molecule positioned at $\mathbf{R}_{\mathrm{A}}$ can be defined by the equation (2) which measures the electrostatic potential at that point due to the continuous electron density and the rest of the nuclei.

$$
V_{\mathrm{n}}=\sum_{\mathrm{B} \# \mathrm{~A}} \frac{\mathrm{Z}_{\mathrm{B}}}{\left|\mathbf{R}_{\mathrm{B}}-\mathbf{R}_{\mathrm{A}}\right|}-\int \frac{\rho\left(\mathbf{r}^{\prime}\right) \mathrm{d}^{3} \mathrm{r}^{\prime}}{\left|\mathbf{r}-\mathbf{r}^{\prime}\right|}
$$

MESP properties of monomers and non-covalent dimers are calculated at MP4/Aug-cc-pvDZ//MP2/6$311++\mathrm{G}+(\mathrm{d}, \mathrm{p})$ level using Gaussian09 ${ }^{63}$ program. Both $V_{\min }$ and $V_{\mathrm{n}}$ have been calculated for all the molecules. The effect of solvent (dichloromethane) in geometries, interaction energies and MESP properties 
of a representative set of non-covalent complexes are also calculated by the SMD solvation model which is based on the quantum mechanical charge density of solute molecule interacting with a continuum description of the solvent ${ }^{64}$ (MP4/Aug-cc-pvDZ-SMD//MP2/ 6-311++G+(d,p)-SMD level calculations, solvent used is dichloromethane).

\section{Results and Discussion}

The HB systems include the conventional systems (electron rich lone pair site of a molecule interacts with hydrogen atom on another molecule) and unconventional systems ( $\pi$-bonds, $\sigma$-bonds and metal atoms act as electron donating centres to electron deficient hydrogen atom on another molecule). Positively charged HB dimers $\left(\mathrm{HB}^{+}\right)$and negatively charged $\mathrm{HB}$ dimers $\left(\mathrm{HB}^{-}\right)$ are also considered. In LiB category, X...Li-Y interaction describes the interaction between an electron rich centre $\mathrm{X}$ and an electropositive Li. In DHB dimers, an electron rich $\mathrm{H}$ center interacts with an electron deficient $\mathrm{H}$ center. For all other cases, viz. $\mathrm{XB}, \mathrm{CB}, \mathrm{PB}$, and $\mathrm{TB}$, the dimers can be grouped under one title, the $\sigma$ hole bonding interactions as portrayed by Politzer et al. In such cases, the electron dense region of one molecule interacts with the electron deficient region, the $\sigma$-hole of another molecule. In Table 1, the systems selected for this study arranged in nine categories, viz., $\mathrm{HB}$, $\mathrm{HB}^{+}, \mathrm{HB}^{-}, \mathrm{CB}, \mathrm{PB}, \mathrm{XB}, \mathrm{LiB}, \mathrm{DHB}$ and $\mathrm{TB}$ are given. The electron donating and withdrawing atoms are indicated in blue and red colour, respectively, wherever possible. Unless otherwise mentioned, hereafter each example (total 54 complexes) will be named by the category name followed by a number that corresponds to the entry number given in Table 1 . For example, HB1 and $\mathrm{HB} 2$ are $\mathrm{HCHO} . . . \mathrm{HF}$ and Guanine...HCl, respectively. Apart from these case studies, complexes such as
$\mathrm{CH}_{3} \mathrm{OH} \ldots \mathrm{HCl}, \mathrm{CO}_{2} \ldots \mathrm{HCl}$ are also discussed for illustrating MESP features.

\subsection{Geometry and Interaction Energy}

The geometries of two representative cases from each category are presented in Figure 1 along with noncovalent interaction distance (d). The $\mathrm{d}$ value of all the systems are presented in Table 2 along with BSSE corrected interaction energy $\left(\mathrm{E}_{\text {int }}\right)$.

Conventional hydrogen bonded complexes involving neutral molecules (HB1-HB6) show $\mathrm{E}_{\text {int }}$ in the range $2.3-7.4 \mathrm{kcal} / \mathrm{mol}$. Similar $\mathrm{E}_{\text {int }}$ range is observed for halogen bonded systems (XB1 - XB6) and dihydrogen bonded systems (DHB1-DHB6). Compared to the anionic $\mathrm{HB}$ complexes $\left(\mathrm{HB}^{-}-\mathrm{HB}^{-}\right)$showing $\mathrm{E}_{\text {int }}$ in the range $1.5-24.1 \mathrm{kcal} / \mathrm{mol}$, the cationic $\mathrm{HB}$ complexes $\left(\mathrm{HB}^{+}-\mathrm{HB}^{+}\right)$display stronger interaction energy $(7.3-32.2 \mathrm{kcal} / \mathrm{mol})$. All the three cationic pnicogen complexes, viz., $\mathrm{F}_{4}^{+} \mathrm{P} . . . \mathrm{NH}_{3}, \mathrm{H}_{2} \mathrm{~F}_{2}^{+} \mathrm{P} . . \mathrm{NCNH}_{2}$, and $\mathrm{H}_{3} \mathrm{~F}^{+} \mathrm{P} .$. $\mathrm{NCCH}_{3}$ show high $\mathrm{E}_{\text {int }}$, viz., 46.2, 33.5, $31.9 \mathrm{kcal} / \mathrm{mol}$, respectively, while the neutral pnicogen complexes display $E_{\text {int }}$ in the range similar to the neutral HB complexes. Similarly, the charged chalcogen complexes, both anionic and cationic show high $\mathrm{E}_{\text {int }}(18.8-27.9 \mathrm{kcal} /$ mol) compared to the neutral ones $(2.5-3.7 \mathrm{kcal} / \mathrm{mol})$. Among the $\mathrm{LiB}$ complexes, $\mathrm{Li}^{+}$interacting with the $\pi$-systems of pyrrole and phenol show high $\mathrm{E}_{\mathrm{int}}$, viz., 37.9 and $35.2 \mathrm{kcal} / \mathrm{mol}$, respectively, and the neutral $\mathrm{Li}$ compounds interacting with the lone pair of $\mathrm{NH}_{3}, \mathrm{CH}_{2}$ and $\mathrm{H}_{2} \mathrm{O}$ show relatively smaller values, viz., 22.2, 19.6 and $17.9 \mathrm{kcal} / \mathrm{mol}$, respectively. In the case of tetrel complexes $\mathrm{E}_{\text {int }}$ are in the range $1.24-16.23 \mathrm{kcal} / \mathrm{mol}$.

\subsection{MESP $V_{\min }$ Analysis}

According to the eDA description of non-covalent interactions, electron donation occurs from the electron

Table 1. Non-covalent complexes in various categories. Blue and red coloured atoms correspond to electron donor and electron acceptor atoms, respectively.

\begin{tabular}{|c|c|c|c|c|c|c|}
\hline System & 1 & 2 & 3 & 4 & 5 & 6 \\
\hline $\mathrm{HB}$ & HCHO...HF & Guanine...HCl & $\mathrm{CH}_{3} \mathrm{OH} \ldots \mathrm{H}_{2} \mathrm{O}$ & $\mathrm{C}_{6} \mathrm{H}_{5} \mathrm{OH} . . . \mathrm{HCl}$ & Pyridine... $\mathrm{C}_{2} \mathrm{H}_{2}$ & $\mathrm{C}_{4} \mathrm{H}_{4} \mathrm{O} \ldots \mathrm{C}_{4} \mathrm{H}_{4} \mathrm{O}$ \\
\hline $\mathrm{HB}^{+}$ & $\mathrm{HCN} \ldots \mathrm{H}_{3} \mathrm{O}^{+}$ & $\mathrm{CH}_{2} \mathrm{O} \ldots \mathrm{CH}_{3} \mathrm{OH}_{2}^{+}$ & $\mathrm{NH}_{3} \ldots \mathrm{NH}_{4}^{+}$ & $\mathrm{CH}_{3} \mathrm{OH} \ldots \mathrm{CH}_{3} \mathrm{NH}_{3}{ }^{+}$ & $\mathrm{H}_{2} \mathrm{O} \ldots \mathrm{NH}_{4}^{+}$ & $\mathrm{CF}_{3} \mathrm{CN} \ldots \mathrm{NH}_{4}^{+}$ \\
\hline $\mathrm{HB}^{-}$ & $\mathbf{F}^{-} \ldots \mathrm{H}_{2} \mathrm{O}$ & $\mathrm{NH}_{2}^{-} \ldots \mathrm{CF}_{3} \mathrm{H}$ & $\mathrm{CH}_{3} \mathrm{NH}^{-} \ldots \mathrm{CF}_{3} \mathbf{H}$ & $\mathrm{Cl}^{-} \ldots \mathrm{HF}$ & $\mathrm{HO}^{-} \ldots \mathrm{HC}_{5} \mathrm{H}_{4} \mathrm{~N}$ & $\mathrm{CH}_{3} \mathrm{O}^{-} \ldots \mathrm{HCHO}$ \\
\hline $\mathrm{CB}$ & $\mathrm{Cl}^{-} \ldots \mathrm{SeClF}$ & $\mathrm{H}_{3} \mathbf{N} \ldots(\mathrm{OH}) \mathrm{H}_{2} \mathrm{~S}^{+}$ & $\mathrm{Cl}^{-} \ldots \mathrm{SFCl}$ & $\mathrm{NH}_{3} \ldots \mathrm{NH}_{2} \mathrm{H}_{2} \mathrm{~S}^{+}$ & HCN...SOFCl & $\mathrm{C}_{2} \mathrm{H}_{2} \ldots \mathrm{SF}_{2}$ \\
\hline PB & $\mathrm{F}_{4}^{+} \mathbf{P} \ldots \mathrm{NH}_{3}$ & $\mathrm{H}_{2} \mathrm{~F}_{2}^{+} \mathbf{P} \ldots \mathrm{NCNH}_{2}$ & $\mathrm{H}_{3} \mathrm{~F}^{+} \mathbf{P} \ldots \mathrm{NCCH}_{3}$ & $\mathrm{H}_{2} \mathrm{FP} \ldots \mathrm{NH}_{3}$ & $\mathrm{H}_{2} \mathrm{O} \ldots \mathrm{C}_{5} \mathrm{NH}_{4} \mathrm{PF}_{2}$ & $\mathrm{PCl}(\mathrm{CN})_{2} \ldots \mathrm{PCl}(\mathrm{CN})_{2}$ \\
\hline XB & $\mathrm{H}_{3} \mathbf{N} \ldots \mathrm{CIF}$ & $\mathrm{H}_{3} \mathbf{N} \ldots \mathrm{BrCN}$ & $\mathrm{HCN} \ldots \mathrm{BrCF}_{3}$ & $\mathrm{ClCN}_{\text {....ClCF }}$ & $\mathrm{H}_{3} \mathbf{N} \ldots \mathrm{ClHSe}$ & $\mathrm{BrCN} \ldots \mathrm{BrCH}_{3}$ \\
\hline TB & $\mathrm{LiCN}_{\ldots} . \mathrm{GeF}_{4}$ & $\mathrm{C}_{6} \mathrm{H}_{5} \mathrm{CN} \ldots \mathrm{GeF}_{3} \mathrm{CN}$ & $\mathrm{MgHF} \ldots \mathrm{SiH}_{3} \mathrm{CN}$ & $\mathrm{HCHO} \ldots \mathrm{CO}_{2}$ & $\mathrm{BeH}_{2} \ldots \mathrm{SiH}_{3} \mathrm{~F}$ & $\mathrm{NO}_{2} \mathrm{C}_{6} \mathrm{H}_{4} \mathrm{CN} \ldots . . \mathrm{CF}_{3} \mathrm{CN}$ \\
\hline $\mathrm{LiB}$ & Pyrrole....Li ${ }^{+}$ & Phenol...Lii ${ }^{+}$ & $\mathrm{H}_{3} \mathbf{N} \ldots \mathrm{LiCN}$ & $\mathrm{H}_{2} \mathrm{C} \ldots \mathrm{LiBr}$ & $\mathrm{H}_{2} \mathbf{O} \ldots \mathrm{LiH}$ & $\mathrm{H}_{2} \mathrm{O} \ldots \mathrm{LiF}$ \\
\hline DHB & $\mathrm{NaH} . . \mathrm{HCN}$ & $\mathrm{MgH}_{2} \ldots \mathrm{HCN}$ & $\mathrm{MgH}_{2} \ldots \mathrm{HBr}$ & $\mathrm{AlH}_{3} \ldots \mathrm{HF}$ & $\mathrm{BeH}_{2} \ldots \mathrm{HC}_{4} \mathrm{H}_{4} \mathrm{~N}$ & $\mathrm{AlH}_{3} \ldots \mathrm{HBr}$ \\
\hline
\end{tabular}


Neutral HB systems

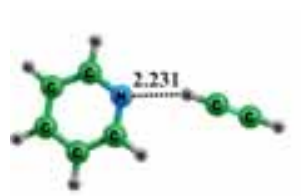

$\mathrm{C}_{5} \mathrm{H}_{5} \mathrm{~N} \ldots \mathrm{C}_{2} \mathrm{H}_{2}$

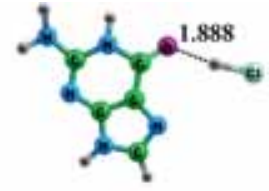

Guanine... HCl

$\underline{\text { Cationic } \mathrm{HB}^{+} \text {systems }}$

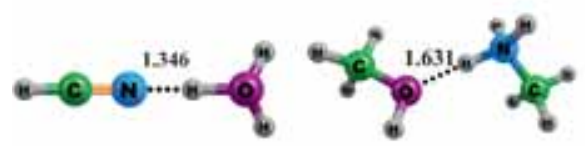

$\mathrm{HCN} . . . \mathrm{H}_{3} \mathrm{O}^{+}$

$\mathrm{CH}_{3} \mathrm{OH} \ldots \mathrm{CH}_{3} \mathrm{NH}_{3}^{+}$

Lithium bonded (LiB) systems
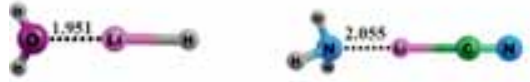

$\mathrm{H}_{2} \mathrm{O}$...LiH

$\mathrm{NH}_{3} \ldots$ LiCN

Chalcogen bonded (CB) systems

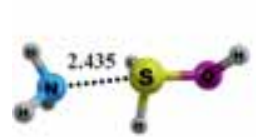

$\mathrm{NH}_{3} \ldots \mathrm{OHH}_{2} \mathrm{~S}^{+}$

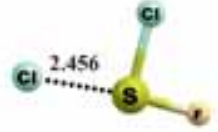

$\mathrm{Cl}^{-}$...SClF

Anionic $\mathrm{HB}^{-}$systems

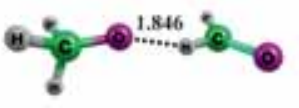

$\mathrm{CH}_{3} \mathrm{O}^{-} \ldots \mathrm{CH}_{2} \mathrm{O}$

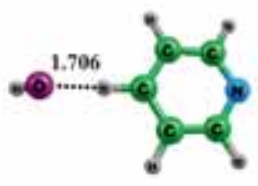

$\mathrm{OH}^{-} \ldots \mathrm{C}_{5} \mathrm{H}_{5} \mathrm{~N}$

$\underline{\text { DHB systems }}$

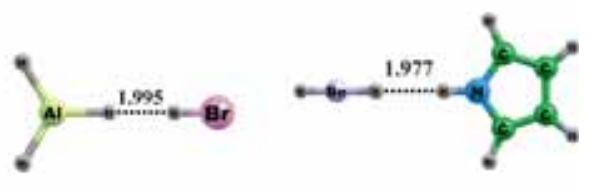

$\mathrm{AlH}_{3} \ldots \mathrm{HBr} \quad \mathrm{BeH}_{2} \ldots$ Pyrrole

$\underline{\text { Halogen bonded (XB) systems }}$

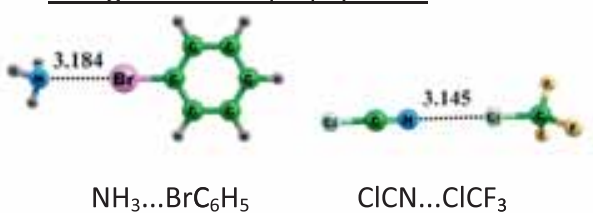

Pnicogen bonded (PB) systems

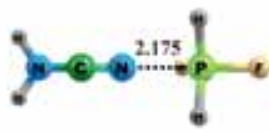

$\mathrm{NH}_{3} \mathrm{CN} \ldots \mathrm{PH}_{2} \mathrm{~F}_{2}^{+}$

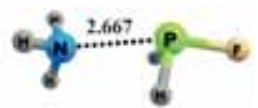

$\mathrm{NH}_{3} \ldots \mathrm{PH}_{2} \mathrm{~F}$

Tetrel bonded (TB) systems

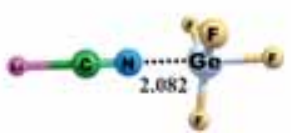

$\mathrm{LiCN}_{\text {...GeF }}$

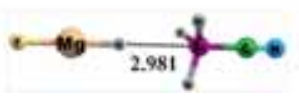

$\mathrm{MgFH} . . . \mathrm{SiH}_{3} \mathrm{CN}$

Figure 1. Optimized geometries of a representative set of non-covalent complexes. All bond lengths in $\AA$.

rich site of the donor molecule to the electron deficient site of the acceptor molecule. As a result, acceptor molecule of the eDA complex becomes electron rich at the expense of the donor molecule. The illustration of this feature can be readily obtained from $V_{\min }$ analysis. From free molecules to eDA complex, a positive change in $V_{\min }$ indicates the loss of electron density while a negative change in $V_{\min }$ indicates the gain of electron density. For instance, by comparing the values of $V_{\min }$ of the conventional $\mathrm{HB}$ complex, $\mathrm{CH}_{3} \mathrm{OH} \ldots \mathrm{H}_{2} \mathrm{O}(\mathrm{HB} 3)$ and its isolated monomers (Figure 2a), we can observe that $V_{\min }$ of $\mathrm{CH}_{3} \mathrm{OH}$ becomes less negative $(-38.65 \mathrm{kcal} / \mathrm{mol})$ in the complex than the free molecule $(-52.79 \mathrm{kcal} / \mathrm{mol})$ while that of $\mathrm{H}_{2} \mathrm{O}$ becomes more negative $(-64.58 \mathrm{kcal} / \mathrm{mol})$ than the free molecule $(-50.77 \mathrm{kcal} / \mathrm{mol})$. This indicates the electron flow from the donor molecule $\mathrm{CH}_{3} \mathrm{OH}$ to the acceptor molecule $\mathrm{H}_{2} \mathrm{O}$. The $V_{\text {min }}$ of $\mathrm{CH}_{3} \mathrm{OH}$... $\mathrm{HCl}$ (Figure 2b) shows that $\mathrm{CH}_{3} \mathrm{OH}$ as electron donor is more effective for $\mathrm{HCl}$ acceptor whereas $V_{\text {min }}$ of $\mathrm{OCO} . . \mathrm{HCl}$ indicates that the accepting power of $\mathrm{HCl}$ becomes weak when $\mathrm{OCO}$ is acting as electron donor (Figure 2c).

Similarly in dihydrogen bonded complexes, for example, $\mathrm{MgH}_{2} \ldots . \mathrm{HCN}$ (DHB5), $V_{\text {min }}$ of $\mathrm{MgH}_{2}$ at the electron donating site $\mathrm{H}$ becomes less negative in the complex compared to the isolated monomer whereas lone pair region of acceptor molecule $\mathrm{HCN}$ becomes 
Table 2. $\mathrm{d}$ in $\AA$ and $\mathrm{E}_{\text {int }}$ in $\mathrm{kcal} / \mathrm{mol}$.

\begin{tabular}{|c|c|c|c|c|c|}
\hline Complex & d $(\AA)$ & $\mathbf{E}_{\text {int }}(\mathrm{kcal} / \mathrm{mol})$ & Complex & $\mathbf{d}(\AA)$ & $\mathbf{E}_{\text {int }(\mathbf{B})}(\mathrm{kcal} / \mathrm{mol})$ \\
\hline HB1 & 1.755 & 7.37 & PB4 & 2.667 & 6.03 \\
\hline HB2 & 1.888 & 6.63 & PB5 & 2.881 & 3.83 \\
\hline HB3 & 1.895 & 4.98 & PB6 & 3.337 & 1.52 \\
\hline HB4 & 2.000 & 4.31 & XB1 & 2.310 & 7.04 \\
\hline HB5 & 2.231 & 3.86 & XB2 & 2.932 & 5.57 \\
\hline HB6 & 2.613 & 2.30 & XB3 & 3.168 & 2.57 \\
\hline $\mathrm{HB}_{1}{ }^{+}$ & 1.346 & 32.20 & XB4 & 3.145 & 1.88 \\
\hline $\mathrm{HB}^{+}{ }^{+}$ & 1.371 & 25.99 & XB5 & 3.080 & 1.28 \\
\hline $\mathrm{HB}^{+}$ & 1.577 & 24.98 & XB6 & 3.345 & 0.70 \\
\hline $\mathrm{HB}_{4}^{+}$ & 1.631 & 19.30 & TB1 & 2.082 & 16.03 \\
\hline $\mathrm{HB}^{+}{ }^{+}$ & 1.649 & 19.29 & TB2 & 2.251 & 5.13 \\
\hline $\mathrm{HB}^{+}{ }^{+}$ & 1.812 & 15.38 & TB3 & 2.981 & 2.14 \\
\hline $\mathrm{HB} 1^{-}$ & 1.387 & 24.11 & TB4 & 2.877 & 1.94 \\
\hline HB2- & 1.761 & 22.23 & TB5 & 2.924 & 1.69 \\
\hline $\mathrm{HB}^{-}{ }^{-}$ & 1.731 & 22.21 & TB6 & 3.440 & 1.24 \\
\hline $\mathrm{HB}_{4}^{-}$ & 1.893 & 21.50 & LiB1 & 1.927 & 37.90 \\
\hline $\mathrm{HB}^{-}$ & 1.706 & 17.99 & $\mathrm{LiB} 2$ & 1.889 & 35.21 \\
\hline $\mathrm{HB}^{-}$ & 1.846 & 15.54 & LiB3 & 2.055 & 22.20 \\
\hline CB1 & 2.467 & 27.92 & LiB4 & 2.188 & 19.58 \\
\hline CB2 & 2.435 & 24.51 & LiB5 & 1.951 & 15.86 \\
\hline CB3 & 2.456 & 22.44 & LiB6 & 1.961 & 15.63 \\
\hline CB4 & 2.672 & 18.78 & DHB1 & 1.803 & 9.00 \\
\hline CB5 & 3.008 & 3.66 & DHB2 & 1.995 & 3.74 \\
\hline CB6 & 3.140 & 2.50 & DHB3 & 1.747 & 3.67 \\
\hline PB1 & 1.923 & 46.21 & DHB4 & 1.683 & 3.21 \\
\hline PB2 & 2.175 & 33.46 & DHB5 & 1.977 & 2.14 \\
\hline PB3 & 2.281 & 31.88 & DHB6 & 1.995 & 1.71 \\
\hline
\end{tabular}

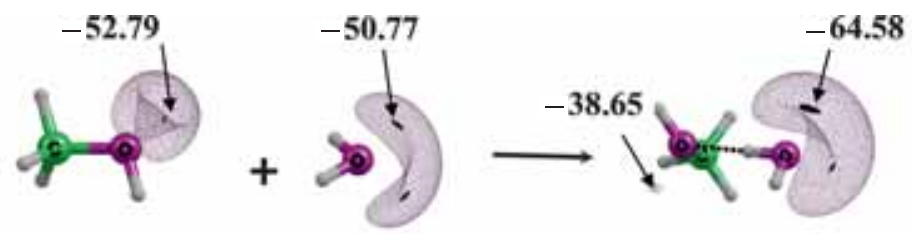

(a)
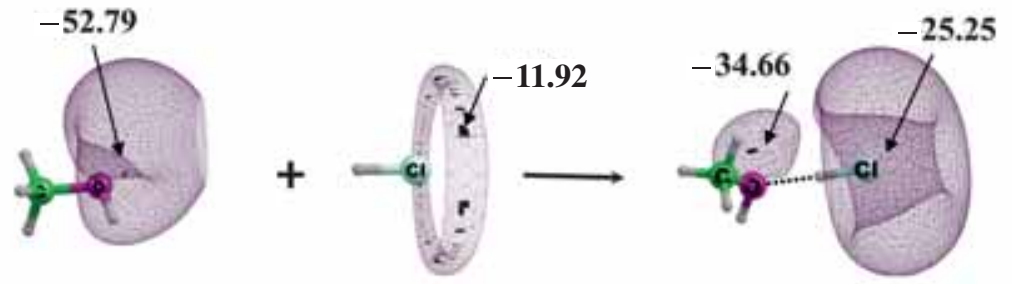

(b)

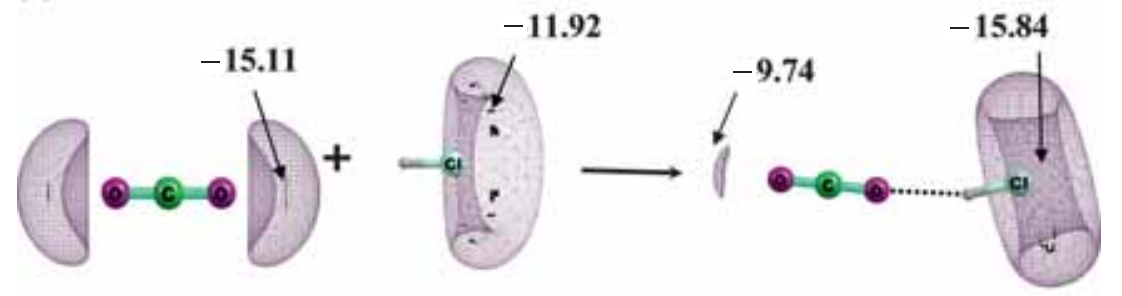

(c)

Figure 2. MESP isosurface plots for hydrogen bonded (HB) complexes and monomers at values (a) -37.65 , (b) -11.30 (c) $-9.41 \mathrm{kcal} / \mathrm{mol}$. $V_{\min }$ values are also indicated in $\mathrm{kcal} / \mathrm{mol}$. 
more negative than the isolated molecule (Figure 3a). The $V_{\min }$ illustrations given in Figure $3 \mathrm{~b}$ and $3 \mathrm{c}$, for $\mathrm{MgH}_{2} \ldots . \mathrm{HBr}$ and $\mathrm{AlH}_{3} \ldots \mathrm{HBr}$, respectively, suggest that the donating power of the donor molecule is strongly related with the accepting power of the acceptor molecule and vice versa.

Similar observations hold good for all the other type of complexes wherein $V_{\min }$ can be determined for the donor and acceptor sites (cationic systems are devoid of $\left.V_{\min }\right)$. The $V_{\min }$ illustrations using the halogen bonded $\mathrm{BrCN}$... $\mathrm{CH}_{3} \mathrm{Br}(\mathrm{XB} 6)$ is presented in Figure 4.

The change in $V_{\min }$ of donor molecule $\left(\Delta V_{\min }(\mathrm{D})\right)$ and that of acceptor molecule $\left(\Delta V_{\min }(\mathrm{A})\right)$ can be considered as the electron donating and accepting power of the donor and acceptor, respectively. Further, according to Mohan and Suresh, the difference between $\Delta V_{\min }(\mathrm{D})$ and $\Delta V_{\min }(\mathrm{A})$, referred to as $\Delta \Delta V_{\min }$ has to be proportional to $\mathrm{E}_{\mathrm{int}}$ (Table 3). ${ }^{61}$ The linear correlation between $\Delta \Delta V_{\min }$ and $\mathrm{E}_{\text {int }}$ given in Figure 5 confirms this hypothesis for all the available systems. Since certain molecules or complexes are devoid of $V_{\min }$, its use to interpret the interaction energy for all types of non-covalent complexes is not possible.

\subsection{MESP $V_{n}$ Analysis}

The MESP value at the donor atom $V_{n}(\mathrm{D})$ and the acceptor atom $V_{n}(\mathrm{~A})$ undergoes significant change during the non-covalent eDA complex formation. The change in MESP observed for the donor atom $\left(\Delta V_{n}(\mathrm{D})\right)$ is proportional to the electron donating ability of the donor molecule while that observed for the acceptor

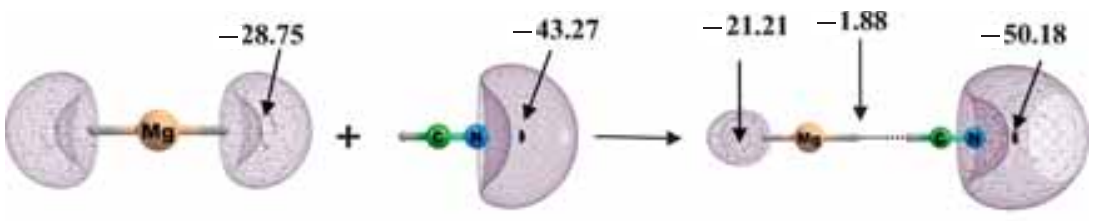

(a)

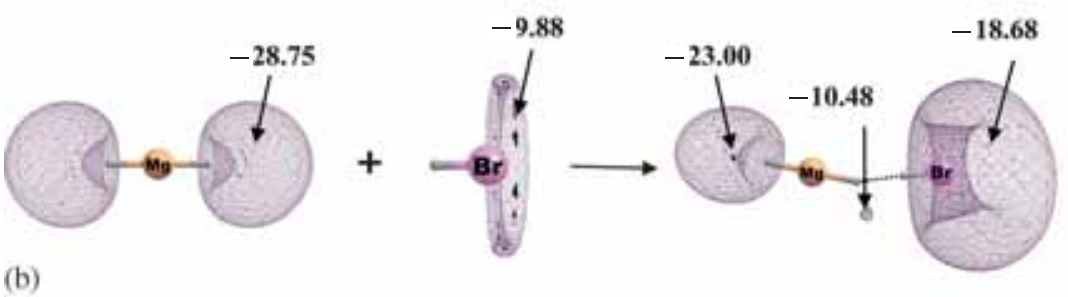

(b)

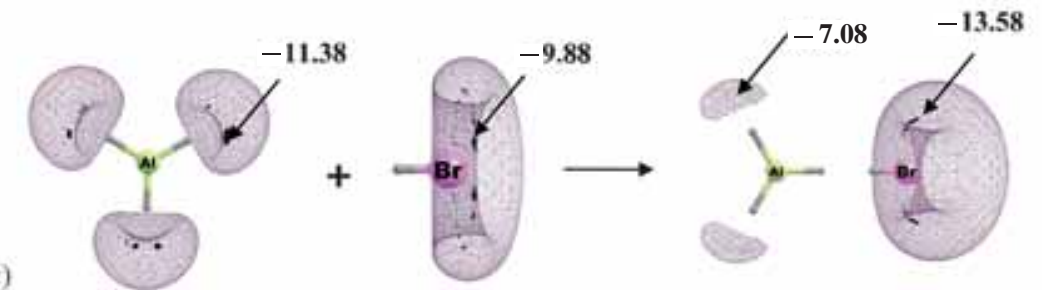

Figure 3. MESP isosurface plots for dihydrogen bonded (HB) complexes and monomers at values (a) -18.83 , (b) -9.41 (c) $-6.28 \mathrm{kcal} / \mathrm{mol}$. $V_{\min }$ values are also indicated in $\mathrm{kcal} / \mathrm{mol}$.

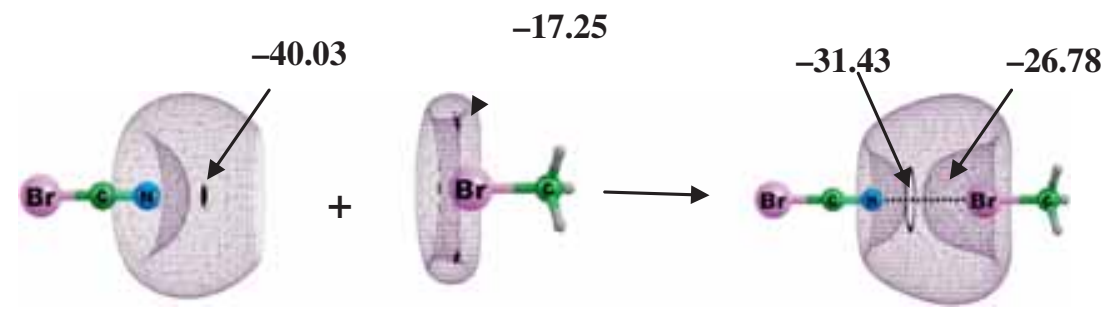

Figure 4. MESP isosurface plots for halogen bonded (HB) complex and monomers at value $-14.43 \mathrm{kcal} / \mathrm{mol}$. $V_{\min }$ values are also indicated in $\mathrm{kcal} / \mathrm{mol}$. 
Table 3. MESP parameters in $\mathrm{kcal} / \mathrm{mol}$ for all the noncovalent complexes.

\begin{tabular}{|c|c|c|c|}
\hline Complex & $\Delta V_{\min }(\mathrm{D})$ & $\Delta V_{\min }(\mathrm{A})$ & $\Delta \Delta V_{\min }$ \\
\hline HB1 & 16.18 & -18.03 & 34.21 \\
\hline HB2 & 21.21 & -26.24 & 47.45 \\
\hline HB3 & 14.14 & -13.81 & 27.95 \\
\hline HB4 & 14.34 & -10.83 & 25.17 \\
\hline HB5 & 29.03 & -9.24 & 38.57 \\
\hline HB6 & 2.94 & -3.63 & 6.58 \\
\hline $\mathrm{HB}^{-}$ & 34.92 & -130.26 & 165.17 \\
\hline $\mathrm{HB}_{2}^{-}$ & 25.65 & -91.12 & 116.77 \\
\hline $\mathrm{HB}^{-}$ & 26.32 & -97.07 & 123.39 \\
\hline $\mathrm{HB}_{4}^{-}$ & 18.99 & -113.47 & 132.46 \\
\hline $\mathrm{HB}^{-}$ & 26.71 & -71.1 & 97.81 \\
\hline $\mathrm{HB}^{-}$ & 21.71 & -92.93 & 114.65 \\
\hline CB1 & 63.77 & -120.17 & 183.94 \\
\hline CB3 & 51.19 & -114.72 & 165.9 \\
\hline CB5 & 10.37 & -12.85 & 23.21 \\
\hline CB6 & 9.88 & -6.96 & 16.84 \\
\hline XB3 & 27.46 & -6.75 & 34.22 \\
\hline XB4 & 21.88 & -5.98 & 27.86 \\
\hline TB4 & 11.11 & -11.94 & 23.04 \\
\hline TB5 & 3.68 & -3.35 & 7.03 \\
\hline DHB1 & 24.45 & -22.02 & 46.47 \\
\hline DHB2 & 26.63 & -6.91 & 33.54 \\
\hline DHB3 & 18.28 & -8.80 & 27.08 \\
\hline DHB4 & 7.11 & -7.89 & 15.01 \\
\hline DHB5 & 5.46 & -2.60 & 8.06 \\
\hline DHB6 & 4.41 & -3.70 & 8.11 \\
\hline
\end{tabular}

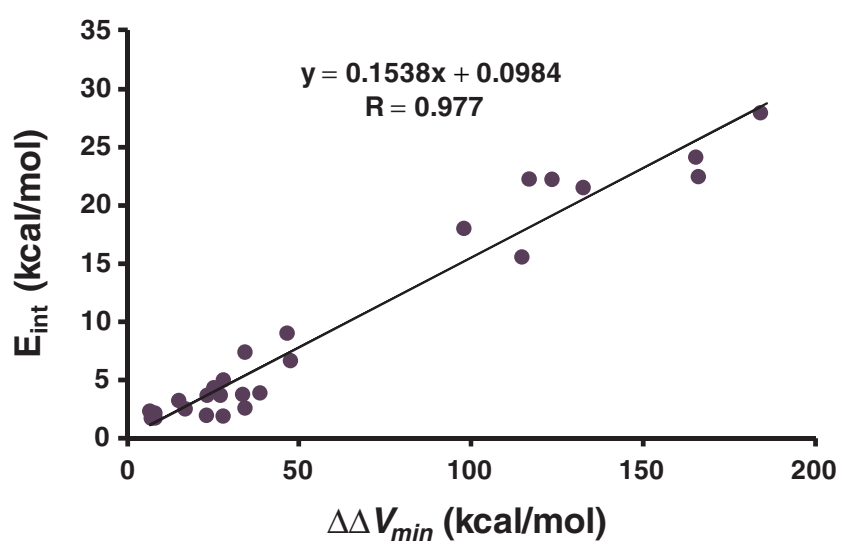

Figure 5. Plot showing the linear correlation between $\Delta \Delta V_{\min }$ and $\mathrm{E}_{\text {int }}$ for the non-covalent complexes.

atom $\left(\Delta V_{\mathrm{n}}(\mathrm{A})\right)$ is proportional to the electron accepting power of the acceptor molecule. On the basis of this interpretation, Mohan and Suresh have shown that the difference between $\Delta V_{n}(\mathrm{D})$ and $\Delta V_{n}(\mathrm{~A})$, referred to as $\Delta \Delta V_{n}$ (Table 4) is proportional to the $\mathrm{E}_{\text {int }}$ of the complex. ${ }^{61}$ This hypothesis is valid for all the complexes studied herein as a good linear correlation between $\Delta \Delta V_{n}$ and $\mathrm{E}_{\text {int }}$ exists (Figure 6).
Table 4. MESP parameters in $\mathrm{kcal} / \mathrm{mol}$ for all the noncovalent complexes.

\begin{tabular}{|c|c|c|c|}
\hline Complex & $\Delta V_{n}(\mathrm{D})$ & $\Delta V_{n}(\mathrm{~A})$ & $\Delta \Delta V_{n}$ \\
\hline HB1 & 22.41 & -24.92 & 47.33 \\
\hline HB2 & 12.09 & -33.03 & 45.12 \\
\hline HB3 & 14.90 & -19.78 & 34.44 \\
\hline HB4 & 15.4 & -13.25 & 28.65 \\
\hline HB5 & 6.29 & -15.02 & 21.31 \\
\hline HB6 & 4.22 & -7.20 & 11.41 \\
\hline $\mathrm{HB}^{+}{ }^{+}$ & 138.31 & -46.62 & 184.94 \\
\hline $\mathrm{HB}_{2}^{+}$ & 134.04 & -33.59 & 167.63 \\
\hline $\mathrm{HB}^{+}{ }^{+}$ & 131.89 & -34.75 & 166.64 \\
\hline $\mathrm{HB}_{4}^{+}$ & 114.32 & -27.00 & 141.32 \\
\hline $\mathrm{HB}^{+}$ & 125.26 & -28.50 & 153.77 \\
\hline $\mathrm{HB}^{+}{ }^{+}$ & 92.88 & -26.33 & 119.21 \\
\hline $\mathrm{HB} 1^{-}$ & 42.28 & -146.82 & 188.48 \\
\hline $\mathrm{HB}^{-}{ }^{-}$ & 19.90 & -125.00 & 145.53 \\
\hline $\mathrm{HB}^{-}$ & 21.34 & -122.63 & 143.97 \\
\hline $\mathrm{HB}_{4}^{-}$ & 22.38 & -137.94 & 160.32 \\
\hline $\mathrm{HB}^{-}$ & 26.67 & -110.77 & 137.44 \\
\hline $\mathrm{HB}^{-}$ & 20.26 & -117.88 & 138.15 \\
\hline CB1 & 63.77 & -120.17 & 183.94 \\
\hline CB2 & 134.33 & -27.25 & 161.58 \\
\hline CB3 & 51.19 & -114.72 & 165.90 \\
\hline CB4 & 112.54 & -22.35 & 134.88 \\
\hline CB5 & 10.37 & -12.85 & 23.21 \\
\hline CB6 & 9.88 & -6.96 & 16.84 \\
\hline PB1 & 218.53 & -49.67 & 268.2 \\
\hline PB2 & 130.56 & -46.67 & 177.23 \\
\hline PB3 & 124.28 & -41.06 & 165.34 \\
\hline PB4 & 20.56 & -18.70 & 39.26 \\
\hline PB5 & 13.68 & -9.16 & 22.84 \\
\hline PB6 & 5.43 & 5.42 & 0.01 \\
\hline XB1 & 38.58 & -23.06 & 61.63 \\
\hline XB2 & 20.19 & -16.08 & 36.26 \\
\hline XB3 & 7.30 & -11.65 & 18.94 \\
\hline XB4 & 4.64 & -10.52 & 15.16 \\
\hline XB5 & 0.39 & -9.51 & 9.90 \\
\hline XB6 & -2.06 & -10.52 & 8.45 \\
\hline TB1 & 57.55 & -56.28 & 113.83 \\
\hline TB2 & 38.36 & -30.51 & 68.86 \\
\hline TB3 & 8.48 & -4.67 & 13.15 \\
\hline TB4 & 5.25 & -14.67 & 19.93 \\
\hline TB5 & 7.88 & -5.31 & 13.29 \\
\hline TB6 & 2.45 & -8.94 & 11.39 \\
\hline LiB1 & 130.08 & -89.70 & 219.78 \\
\hline LiB2 & 119.30 & -92.21 & 211.51 \\
\hline LiB3 & 61.10 & -54.98 & 116.08 \\
\hline LiB4 & 52.16 & -52.37 & 104.52 \\
\hline LiB5 & 54.31 & -47.60 & 101.91 \\
\hline LiB6 & 54.96 & -49.44 & 104.41 \\
\hline DHB1 & 2.87 & -37.79 & 40.66 \\
\hline DHB2 & 11.87 & -13.52 & 25.4 \\
\hline DHB3 & 9.71 & -9.05 & 18.76 \\
\hline DHB4 & 13.64 & -11.62 & 25.26 \\
\hline DHB5 & 12.68 & -5.95 & 18.62 \\
\hline DHB6 & 8.39 & -4.30 & 12.69 \\
\hline
\end{tabular}




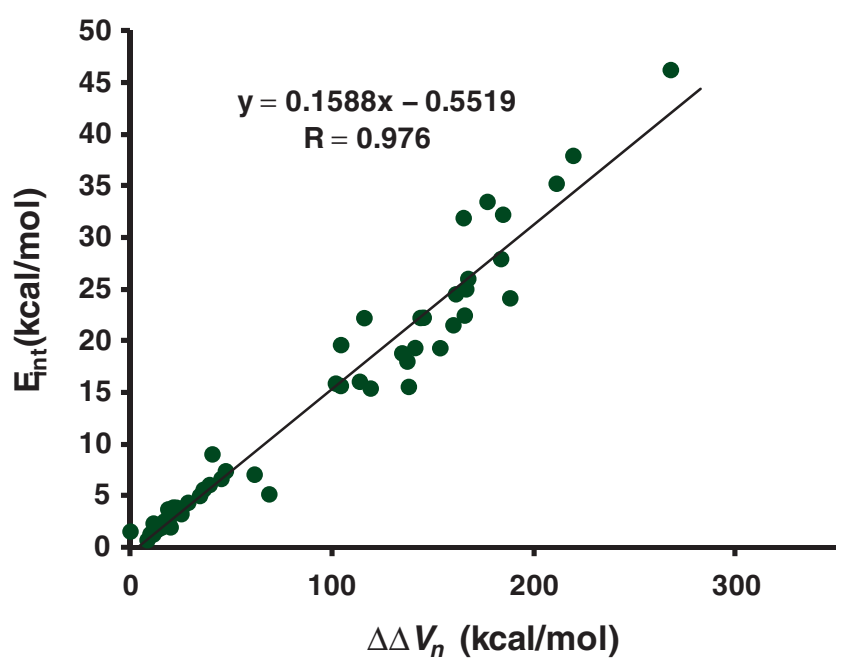

Figure 6. Plot showing the linear correlation between $\Delta \Delta V_{n}$ and $\mathrm{E}_{\text {int }}$ for all the non-covalent complexes.

Table 5. MESP parameters and intertaction energy $\left(E_{\text {int }}\right)$ in $\mathrm{kcal} / \mathrm{mol}$ (solvent phase) for a representative set of noncovalent complexes.

\begin{tabular}{lrrrr}
\hline Complex & $\Delta V_{n}(\mathrm{D})$ & $\Delta V_{n}(\mathrm{~A})$ & $\Delta \Delta V_{n}$ & \multicolumn{1}{c}{$\mathrm{E}_{\text {int }}$} \\
\hline HB1 & 28.51 & -42.95 & 71.46 & 7.54 \\
HB3 & 17.85 & -27.33 & 45.18 & 4.99 \\
$\mathrm{HB}^{+}$ & 140.48 & -54.64 & 195.12 & 14.05 \\
$\mathrm{HB}^{+}$ & 141.79 & -42.52 & 184.31 & 13.99 \\
$\mathrm{HB}^{-}$ & 32.48 & -165.30 & 197.78 & 9.48 \\
$\mathrm{HB}^{-}$ & 22.53 & -154.52 & 177.05 & 6.38 \\
CB5 & 15.79 & -18.06 & 33.85 & 4.76 \\
CB6 & 13.36 & -8.11 & 21.47 & 4.03 \\
PB4 & 49.19 & -26.16 & 75.34 & 10.06 \\
PB5 & 18.26 & -12.47 & 30.73 & 4.63 \\
XB1 & 134.04 & -31.19 & 165.23 & 23.28 \\
XB2 & 28.42 & -17.97 & 46.39 & 7.13 \\
TB1 & 78.15 & -74.93 & 153.08 & 28.16 \\
TB3 & 26.66 & -8.87 & 35.53 & 3.12 \\
LiB3 & 70.29 & -53.60 & 123.89 & 20.17 \\
LiB5 & 62.16 & -53.77 & 115.92 & 13.85 \\
DHB2 & 28.50 & -23.49 & 51.99 & 2.11 \\
DHB4 & 24.38 & -16.15 & 40.53 & 2.59 \\
\hline
\end{tabular}

MP4/Aug-cc-pvDZ-SMD//MP2/6-311++g(d,p)-SMD level interaction energy $\left(\mathrm{E}_{\mathrm{int}}\right)$ and MESP properties of two complexes from each category are summarised in Table 5. The $\Delta \Delta V_{n}$ correlates linearly with $\mathrm{E}_{\text {int }}$ in the case of neutral complexes whereas charged species deviates significantly from this plot. This can be attributed to the large solvation effect experienced by the charged species as their solvation effect incorporated interaction energy is much lower than the gas phase results (Figure 7).

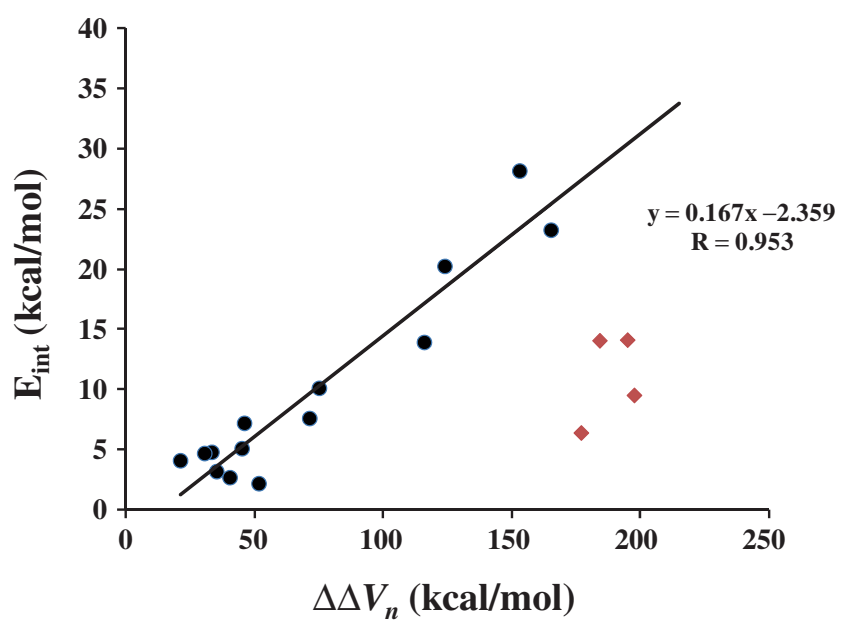

Figure 7. Plot showing the linear correlation between $\Delta \Delta V_{n}$ and $\mathrm{E}_{\text {int }}$ for a representative set of neutral complexes in solvent phase. Circle and diamond symbols represent neutral and charged complexes, respectively.

\section{Conclusions}

High accuracy $a b$ initio calculations have been performed on a large variety of non-covalent dimers in order to investigate the applicability of molecular electrostatic potential (MESP) based parameters to interpret the non-covalent bond formation. This type of analysis has been previously reported for the well established interactions such as hydrogen, dihydrogen and halogen bonds and interpreted them as electron donoracceptor (eDA) interactions. ${ }^{61}$ The results presented in this study clearly suggest that the non-covalent interactions present in lithium bond, tetrel bond, pnicogen bond and chalcogen bond can be grouped under the general category of eDA interactions. The eDA complex formation for a representative set of complexes has been illustrated using MESP isosurface and MESP minimum $\left(V_{\min }\right)$. The electron donating ability of the donor molecule is obtained in terms of the difference between change in $V_{\min }$ of the donor molecule or the change in $V_{\mathrm{n}}$ of the donor atom with respect to the eDA complex while the electron accepting ability of the acceptor is related with the corresponding $V_{\min }$ or $V_{\mathrm{n}}$ change at the acceptor molecule or the acceptor atom. The interaction energy is found to be the highest when a strongly electron donating molecule interacts with a strongly electron accepting molecule. The good linear correlations obtained between $\Delta \Delta V_{\text {min }}$ and $\mathrm{E}_{\text {int }}$ as well as between $\Delta \Delta V_{\mathrm{n}}$ and $\mathrm{E}_{\mathrm{int}}$ validate the interpretation that in anytype of non-covalent complexes studied herein, certain degree of electron donation and acceptance occurs which is directly proportional to the energy released during bond formation. Thus, in agreement with Mohan and Suresh ${ }^{61}$ the MESP based eDA concept holds good 
for all type of non-covalent interactions that have been analyzed in the gas phase. Calculations on a representative set of molecules have shown that in solvent phase, $\Delta \Delta V_{\mathrm{n}}$ versus $\mathrm{E}_{\mathrm{int}}$ linear correlation is valid for neutral complexes whereas the charged species may deviate from this plot due to large changes in the interaction energy.

\section{Supplementary Information (SI)}

SCF energies and BSSE for MP2 and MP4 methods are given in the Supplementary Information, available at www.ias.ac.in/chemsci.

\section{Acknowledgements}

This research work is supported by the Council of Scientific and Industrial Research (CSIR), Govt. of India, through a project CSC0129 and PVB is thankful to CSIR for the research fellowship.

\section{References}

1. Bernstein J, Davis R E, Shimoni L and Chang N L 1995 Angew. Chem. Int. Ed. 341555

2. Aakeroy C B, Panikkattu S, Chopade P D and Desper J 2013 CrystEngComm 153125

3. Whitesides G M and Grzybowski B 2002 Science 295 2418

4. Desiraju G R 2002 Acc. Chem. Res. 35565

5. Son S U, Reingold J A, Carpenter G B and Sweigart D A 2006 Chem. Commun. (Camb) 708

6. Jeffrey G A and Saenger W 2012 In Hydrogen bonding in biological structures (Berlin: Springer Science \& Business Media)

7. Grabowski S J 2006 In Hydrogen bonding: New insights (Netherlands: Springer) p. 149

8. Desiraju G R 2011 Angew. Chem. Int. Ed. 5052

9. Arunan E, Desiraju G R, Klein R A, Sadlej J, Scheiner S, Alkorta I, Clary D C, Crabtree R H, Dannenberg J J and Hobza P 2011 Pure Appl. Chem. 831619

10. Wolstenholme D J, Dobson J L and McGrady G S 2015 Dalton Trans. 49718

11. Kulkarni S A 1998 J. Phys. Chem. A 1027704

12. Custelcean R and Jackson J E 2001 Chem. Rev. 1011963

13. Politzer P, Lane P, Concha M C, Ma Y and Murray J S 2007 J. Mol. Model. 13305

14. Clark T, Hennemann M, Murray J S and Politzer P 2007 J. Mol. Model. 13291

15. Metrangolo P and Resnati G 2001 Chem. Eur. J. 72511

16. Politzer P, Murray J S and Clark T 2010 Phys. Chem. Chem. Phys. 127748

17. Desiraju G R and Parthasarathy R 1989 J. Am. Chem. Soc. 1118725

18. Pedireddi V, Reddy D S, Goud B S, Craig D C, Rae A D and Desiraju G R 1994 J. Chem. Soc., Perkin Trans. 22353

19. Nagao Y, Hirata T, Goto S, Sano S, Kakehi A, Iizuka K and Shiro M 1998 J. Am. Chem. Soc. 1203104
20. Zahn S, Frank R, Hey-Hawkins E and Kirchner B 2011 Chem. Eur. J. 176034

21. Del Bene J E, Alkorta I, Sanchez-Sanz G and Elguero J 2012 J. Phys. Chem. A 1169205

22. Alkorta I, Sanchez-Sanz G, Elguero J and Del Bene J E 2014 J. Phys. Chem. A 1181527

23. Nziko V d P N and Scheiner S 2014 J. Phys. Chem. A 11810849

24. Ramasami P and Ford T A 2015 J. Mol. Model. 211

25. Brezgunova M E, Lieffrig J, Aubert E, Dahaoui S, Fertey P, S b Lebegue, Angyan J n G, Fourmigue M and Espinosa E 2013 Cryst. Growth Des. 133283

26. Wang W, Ji B and Zhang Y 2009 J. Phys. Chem. A 113 8132

27. Bleiholder C, Werz D B, Köppel H and Gleiter R 2006 J. Am. Chem. Soc. 1282666

28. Gleiter R, Werz D B and Rausch B J 2003 Chem. Eur. J. 92676

29. Grabowski S J 2014 Phys. Chem. Chem. Phys. 161824

30. Esrafili M D, Mohammadirad N and Solimannejad M 2015 Chem. Phys. Lett. 62816

31. Azofra L M and Scheiner S 2015 J. Chem. Phys. 142034307

32. Bauzá A, Mooibroek T J and Frontera A 2013 Angew. Chem. 12512543

33. Mani D and Arunan E 2013 Phys. Chem. Chem. Phys. 1514377

34. Ault B S and Pimentel G C 1975 J. Phys. Chem. 79621

35. Szczęśniak M, Ratajczak H, Agarwal U P and Rao C 1976 Chem. Phys. Lett. 44465

36. Scheiner S 1995 In Lithium Chemistry: A Theoretical and Experimental Overview (New York: John Wiley \& Sons, Inc.) 67

37. Grabowski S J 2001 J. Phys. Chem. A 10510739

38. Belkova N V, Shubina E S and Epstein L M 2005 Acc. Chem. Res. 38624

39. Gilli G and Gilli P 2000 J. Mol. Struct. 5521

40. Gilli G and Gilli P 2009 In The nature of the hydrogen bond: Outline of a comprehensive hydrogen bond theory (Oxford: OUP)

41. Coulson C 1957 Research 10149

42. Pimentel G C and McClellan A L 1960 In The hydrogen bond (San Francisco: WH Freeman)

43. Crabtree R H, Siegbahn P E, Eisenstein O, Rheingold A L and Koetzle T F 1996 Acc. Chem. Res. 29348

44. Richardson T, de Gala S, Crabtree R H and Siegbahn P E 1995 J. Am. Chem. Soc. 11712875

45. Sannigrahi A, Kar T, Niyogi B G, Hobza P and Schleyer P v R 1990 Chem. Rev. 901061

46. Politzer P, Murray J S and Clark T 2013 Phys. Chem. Chem. Phys. 1511178

47. Politzer P, Murray J S, Janjić G V and Zarić S D 2014 Crystals $\mathbf{4} 12$

48. Wang C, Guan L, Danovich D, Shaik S and Mo Y 2016 J. Comput. Chem. 3734

49. Sajith P and Suresh C H 2011 Inorg. Chem. 508085

50. Galabov B and Bobadova-Parvanova P 1999 J. Phys. Chem. A 1036793

51. Galabov B, Bobadova-Parvanova $\mathrm{P}$, Ilieva $\mathrm{S}$ and Dimitrova V 2003 J. Mol. Struct: Theochem. 630101

52. Murray J S and Politzer P 2011 WREs. Comput. Mol. Sci. 1153 
53. Gadre S R and Bhadane P K 1999 Resonance 414

54. Gadre S R and Shirsat R N 2000 In Electrostatics of atoms and molecules (Hyderabad, India: Universities Press)

55. Goldwasser J, Murray J S and Politzer P 1998 In The Molecular Electrostatic Potential: A Tool for Understanding and Predicting Molecular Interaction (Fort Belvoir: DTIC-Defense Technical Information Center)

56. Murray J S, Lane P, Clark T, Riley K E and Politzer P 2012 J. Mol. Model. 18541

57. Murray J S, Paulsen K and Politzer P 1994 Indian Acad. Sci. (Chem. Sci.) 106267

58. Politzer P and Truhlar D G (Eds.) 1981 In In Chemical applications of atomic and molecular electrostatic potentials: Reactivity, structure, scattering, and energetics of organic, inorganic, and biological systems (US: Springer Science \& Business Media)

59. Sandhya K S, Remya G S and Suresh C H 2015 Inorg. Chem. 5411150

60. Pullman A and Pullman B 1981 In Chemical Applications of Atomic and Molecular Electrostatic Potentials $\mathrm{P}$ Politzer and D Truhlar (Eds.) (New York: Plenum Press) p. 381
61. Mohan N and Suresh C H 2014 J. Phys. Chem. A 118 1697

62. Boys S F and Bernardi F 1970 Mol. Phys. 19553

63. Frisch M J, Trucks G W, Schlegel H B, Scuseria G, Robb M A, J R, Cheeseman J R, Scalmani G, BaroneV, Mennucci B, Petersson G A, Nakatsuji H, Caricato M, Li X, Hratchian H P, Izmaylov A F, Bloino J, Zheng G, Sonnenberg J L, Hada M, Ehara M, Toyota K, Fukuda R, Hasegawa J, Ishida M, Nakajima T, Honda Y, Kitao O, Nakai H, Vreven T, Montgomery J A, Jr., Peralta J E, Ogliaro F,Bearpark M, Heyd J J, Brothers E, Kudin K N, Staroverov V N, Keith T, Kobayashi R, Normand J, Raghavachari K, Rendell A, Burant J C, Iyengar S S, Tomasi J, Cossi M, Rega N, Millam J M, Klene M, Knox J E, Cross J B, Bakken V, Adamo C, Jaramillo J, Gomperts R, Stratmann R E, Yazyev O, Austin A J, Cammi R, Pomelli C, Ochterski J W, Martin R L, Morokuma K, Zakrzewski V G, Voth G A, Salvador P, Dannenberg J J, Dapprich S, Daniels A D, Farkas O, Foresman J B, Ortiz J V, Cioslowski J and Fox D J 2013 Gaussian 09, Revision D.01 (Gaussian, Inc.: Wallingford CT)

64. Marenich A V, Cramer C J and Truhlar D G 2009 J. Phys. Chem. B 1136378 